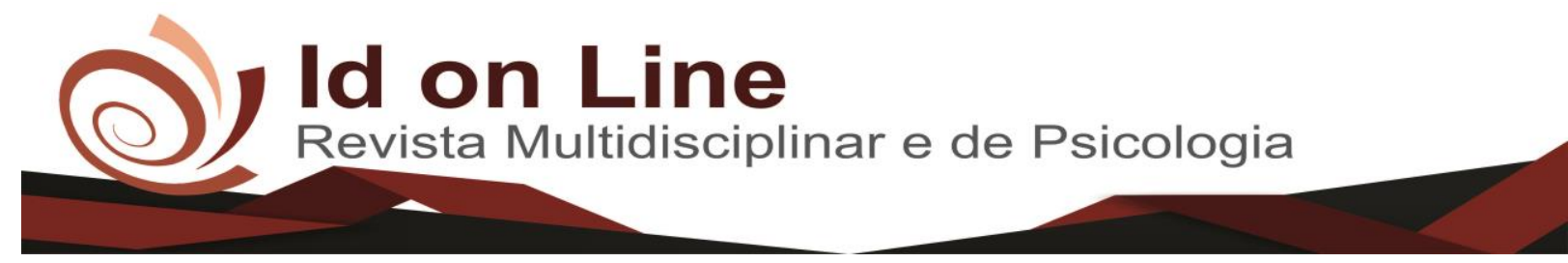

Editorial

\title{
Onde Publicar Seu Artigo Científico?
}

Gislene Farias de Oliveira ${ }^{1}$; Hermes Melo Teixeira Batista ${ }^{2}$

Resumo: Os periódicos científicos hoje são muito diversificados, desde os mais generalistas até os mais específicos. É grande a diversidade de possibilidades. Daí, é comum a indagação pelos pesquisadores: como selecionar o periódico mais adequado ao meu artigo científico? Este editorial discute sobre alguns critérios que se deve levar em conta, no momento de tal escolha. Dentre os quais: observar os periódicos que publicam assuntos similares ao de sua pesquisa, a qualidade das revistas, dados os referenciais de fator de Impacto, Qualis e, base de dados onde está abrigado o periódico, são pistas importantes. Este aparato é de grande importância, pois visa resguardar os bons artigos para que tenham boa visibilidade pelos pares.

Palavras-chave: Periódicos científicos, Pesquisa, Revistas científicas.

\section{Where to Publish Your Scientific Article?}

\begin{abstract}
Scientific journals today are very diverse, from the most general to the most specific. The diversity of possibilities is great. Hence, it is common to ask the researchers: how to select the most appropriate journal for my scientific article? This editorial discusses some criteria that should be taken into account at the time of such choice. Among them: observing the journals that publish subjects similar to those of their research, the quality of the journals, given the references of Impact factor, Qualis, and database where the journal is housed, are important clues. This apparatus is of great importance, since it aims to protect good articles so that they have good visibility by the peers.
\end{abstract}

Keywords: Scientific journals, Research, Scientific journals.

\section{Introdução}

Hoje em dia há muitos periódicos científicos disponíveis no mundo inteiro. Ante essa vasta diversidade bibliográfica, como definir a revista que vai abrigar sua pesquisa mais recente?

Os periódicos são muito diversificados. Há aqueles mais específicos em uma determinada área do conhecimento (Revista Brasileira de Enfermagem) e, há outros mais generalistas (Caderno de Cultura e Ciência), que abrigam muitas áreas da ciência ao mesmo tempo.

\footnotetext{
${ }^{1}$ Psicóloga. Doutorado em Psicologia social pela UFPB. Professora da Faculdade de Medicina da Universidade Federal do Cariri. Contato: gislenfarias@gmail.com.

${ }^{2}$ Doutorando em Ciências da Saúde pela FMABC, Médico do Hospital Universitário Júlio Bandeira - HUJB, Cajazeiras, PB, Professor de Emergências médica da Estácio, FMJ. Contato: hermesmelo@oi.com.br.
} 
O universo é muito amplo em termos de quantidade de revistas, somente a exemplo, na Plataforma Sucupira, há 3850 periódicos que tratam sobre biodiversidade, 3026 que tratam sobre psicologia e, outros 3992 que tratam sobre educação (CAPES - PLATAFORMA SUCUPIRA, 2018).

Portanto, a escolha de uma revista parece ser um grande desafio para o pesquisador. É importante recordar que há pouco mais de uma década, publicar não era algo tão complicado como hoje. Considere-se que havia um número bem menor de revistas científicas, portanto o universo de escolha também não era grande. Outra situação era que não havia muita referência ao tão "famigerado" Fator de impacto, daí a escolha era com base no assunto da revista e no próprio prestígio que gozava o periódico no meio acadêmico.

Essa discussão por uma construção coletiva de um saber, não engessado que seja plural e ético, é uma tentativa de elucidar a comunidade acadêmica, sobre uma problemática que apode vir a afetar a produção científica brasileira e, dos países vizinhos. Verifica-se que, apesar das importantes iniciativas como SciELO e Redalyc, ainda há preconceito quanto ao banco de dados em que se abriga o artigo, como demonstra Beall (2015).

$\mathrm{Na}$ prática, a escolha acontecia da seguinte maneira: primeiro, observar os periódicos que publicassem assuntos similares ao de sua pesquisa. Em um segundo momento, conversávamos com pessoas do meio acadêmico sobre a qualidade das revistas e seu conceito e amplitude de distribuição.

Assim, com base nessa avaliação subjetiva, tomava-se uma decisão sobre qual(is) revista(s) pareciam mais adequadas para o artigo em questão. Ante as eleitas, se decidia em qual investir. Todos intuíam que era preciso mandar um manuscrito atualizado um periódico que estivesse divulgando sobre o mesmo assunto e, que fosse mais aceito pelos pares profissionais.

Observe-se que era um trabalho bastante minucioso, baseado em uma leitura mais frequente e aprofundada, além da informação de pesquisadores mais experientes. Hoje já não se toma a decisão dessa maneira. Nas últimas décadas, cresceram as opções de publicações e, as boas revistas parecem estarem sob a guarda de grandes editoras internacionais. Além disso, apareceram outros parâmetros para referenciar os periódicos, dentre eles o Fator de Impacto.

O Fator de Impacto parece ter-se tornado um dos principais critérios utilizados pela maioria dos pesquisadores no momento da escolha do periódico a publicar seus achados acadêmicos e científicos. Em resumo, isso significa que, os artigos, quanto mais citados em 
veículos abrigados nas bases de dados, mais atraente ele vai parecer ante a comunidade científica, numa determinada área. Mas, o Fator de Impacto por si só, não consiste em única ou melhor medida da qualidade de um periódico. Há outros critérios qualitativos que precisam ser levados em conta, a exemplo do histórico, quantidade de artigos publicados ao ano ou a reputação do mesmo.

\section{Critérios para a seleção do periódico}

Neste caso, haveria uma forma ou check list para a escolha sobre onde publicar?

Embora difícil, é importante que o artigo seja publicado em revistas que estejam indexadas em boas bases de dados. As mais recomendadas seriam: Scopus, Scielo, Web of Science. Numa segunda linha: Eric, Latindex, Redalyc, DAOJ, DRJI, AE Global Index e outras.

O que é importante considerar:

a) Sobre os periódicos que publicam artigos com assunto similar ao que pretende publicar;

b) Dentre essas primeiras, qual(is) sente maior afinidade? Rapidez na avaliação; facilidade de contato com o editor; qualidade da avaliação;

c) Sobre a aceitação da revista no meio acadêmico; Fator de Impacto; Estatística sobre os acessos e downloads dos artigos;

d) Pesar sobre gratuidade (mais comum) ou se são pagas (e o que oferecem em contrapartida em termos de qualidade). Alguns periódicos encontram-se sob a guarda de grandes editoras que restringem o acesso através uma inscrição. Isso é, não são open access, portanto restringindo, neste segundo caso, a visualização do seu artigo completo apenas aos assinantes. Inclusive cobrando por esse acesso. Trata-se de uma prática comum no mundo, não vista com bons olhos no Brasil, mesmo que a maioria das universidades, não destine nenhum recurso para publicações dos seus pesquisadores.

e) A referência Qualis-CAPES é algo bastante aceito no Brasil e, portanto, deve ser levando em conta, pois muitas das pontuações obtidas em certames de seleção para professores, mestrados doutorados, levam em conta esta referência. 
Finalmente, ter atenção a esses critérios ajuda na escolha do periódico que irá abrigar seu trabalho. Quanto mais atento aos objetivos e método adequados, assunto mais atual, mais chance de aprovação.

Lembrar que a aprovação depende da avaliação por pares e, o manuscrito pode, em muitos casos ser rejeitado numa primeira tentativa. Neste caso, levando em conta as considerações dos avaliadores, pode-se ajustar e submeter-se a outro periódico, se você acredita na qualidade da sua produção. Afinal, um bom trabalho não deve ser "esquecido" em uma gaveta. Deve ser publicado, de forma que a comunidade científica tenha conhecimento e possa criticar ou aplaudir, beneficiando-se deste novo conhecimento acadêmico.

\section{Referências}

BEALL J. Is SciELO a publication favela? Scholarly Open Access. [Internet]. 30 jul 2015. [acesso 15 nov 2018]. Disponível: http://scholarlyoa.com/2015/07/30/is-scielo-a-publicationfavela/.

CAPES - Coordenação de Aperfeiçoamento de Pessoal de Nível Superior. Periódicos Qualis 2013- 2016. Plataforma Sucupira. [Internet]. [acesso 15 nov 2018]. Disponível: https://sucupira.capes.gov.br/sucupira/.

\section{Como citar este artigo (Formato ABNT):}

OLIVEIRA, Gislene Farias de; BTISTA, Hermes Melo Teixeira. Onde Publicar seu Artigo Científico? Id on Line Rev.Mult. Psic., 2018, vol.12, n.42, Supl. 1, p. 548-551. ISSN: 1981-1179.

Recebido: 08/11/2018;

Aceito: $15 / 11 / 2018$ 